\title{
Cationic Polymerization of 1- and 2-Vinylnaphthalenes
}

\author{
Claude Bunel and Ernest MARechal \\ Laboratoire de Chimie Macromoléculaire, \\ Institut National Supérieur de Chimie Industrielle de Rouen \\ B. P. 08-76130 Mont Saint-Aignan, France et \\ Laboratoire de Synthèse Macromoléculaire Université de Paris VI \\ Tour 44, ler étage-4, Place Jussieu \\ 75230 Paris Cedex 05, France.
}

(Received April 23, 1977)

\begin{abstract}
The cationic polymerization of 1- and 2-vinylnaphthalenes has been studied. The polymers have low molecular weights; this is due to transfer reactions and in agreement with the results of quantum chemical calculations. The kinetic characteristics of 1-vinylnaphthalene have been determined in high purity conditions. Only one determination has been done with 2-vinylnaphthalene. The result shows that the rates of polymerization for the two monomers are the same, at least under the experimental conditions in this work. This observation is in agreement with reactivity ratios previously determined and the stabilization energy obtained by the Hückel method.
\end{abstract}
KEY WORDS 1-Vinylnaphthalene / 2-Vinylnaphthalene / Cationic Polymerization / Rate Constants / Reactivity Ratios / Hückel Method / Enthalpy of Polymerization /

Several of our previous papers ${ }^{1-7}$ have dealt with the cationic polymerization of vinyl aromatic monomers with condensed rings. We studied their reactivity both by quantum chemistry and by the determination of reactivity ratios. In the present paper we describe work on 1- and 2vinylnaphthalenes. Although there are many publications concerning their anionic, radical, or Ziegler-Natta polymerizations, there are only three references to their cationic polymerization, ${ }^{8-10}$ without any physicochemical information.

\section{EXPERIMENTAL}

\section{Materials}

Vinylnaphthalenes. Both monomers were synthesized by the methods of Berger ${ }^{11}$ and Davies and Porter, ${ }^{12}$ through the dehydration of 2-(1naphthyl)- and 2-(2-naphthyl) ethanol catalyzed by $\mathrm{KHSO}_{4}$ in vacuo. The monomers were stored in vacuo in graduated tubes fitted with break seals. 1 -Vinylnaphthalene: yield, $50 \% ; n_{\mathrm{D}}^{20}, 1.6436 ; \mathrm{bp}$, $80^{\circ} \mathrm{C}(0.5 \mathrm{~mm})$. 2-Vinylnaphthalene: yield, $50 \%$; $\mathrm{mp}, 66^{\circ} \mathrm{C}$.
1-Vinyl-4-methoxynaphthalene. The 1-acetyl-4methoxynaphthalene was prepared by the reaction of acetyl chloride $(0.5 \mathrm{~mol})$ with 1 -methoxynaphthalene $(0.5 \mathrm{~mol})$ in benzene $(800 \mathrm{ml})$ in the presence of $\mathrm{TiCl}_{4}$. The duration of the reaction was 2 days at room temperature: yield, $75 \% ; \mathrm{mp}$, $71^{\circ} \mathrm{C}$. This ketone was reduced to (4-methoxy-1naphthyl)methyl carbinol by $\mathrm{AlLiH}_{4}$ and the alcohol was distilled under vacuum to obtain 1vinyl-4-methoxynaphthalene: yield, $35 \%$; $\mathrm{mp}$, $36^{\circ} \mathrm{C}$.

Dichloromethane was purified by Nguyen Anh Hung's technique ${ }^{17}$ and kept in vacuo in a graduated tube or polymerizing apparatus. Ethyl chloride was purified by distillation.

\section{Procedures}

The polymerizations have been run in a sealed apparatus in vacuo. In all experiments but one the solvent was $\mathrm{CH}_{2} \mathrm{Cl}_{2}$. The methods for the purification in vacuo have been developed by Fontanil$1 \mathrm{e}^{13}$ and made suitable for cationic polymerization by Cheradame, et al., ${ }^{14,15}$ and Vairon, et al. ${ }^{16}$

Titanium tetrachloride was dissolved in Dich- 


\section{BunEL and E. MAREChal}

loromethane at the chosen concentration and stored in vacuum ampoules which can be introduced into the polymerization apparatus.

We used the technique developed by Cheradame ${ }^{18}$ from that of Plesch. ${ }^{19}$ The procedure for thermodynamic and kinetic measurements is described later. The time elapsed between the introduction of the initiator and of the terminator in the monomer solution is $5 \mathrm{~min}$. The intrinsic viscosity $[\eta]$ was measured at $25^{\circ} \mathrm{C}$ in benzene; the unit is $100 \mathrm{~cm}^{3} \mathrm{~g}^{-1}$.

\section{RESULTS}

\section{Homopolymerization of 1-Vinylnaphthalene}

The results obtained with various initiators are listed in Table I.

When the initiator is $\mathrm{TiCl}_{4}$, the values of monomer concentration [M] (in the range 0.05-0.4 M) and of initiator concentration [C] (in the range 0.005-0.08 M) have no influence on the yield, which was always quantitative, and have only a very small influence on $[\eta]$. However, when [C]

Table I. Variations of the yield and $[\eta]$ with the nature of the initiator

(A) 1-Vinylnaphthalene: $[\mathrm{M}]=0.155 \mathrm{M}$;

\begin{tabular}{lcrc}
\multicolumn{5}{c}{$\theta=-72^{\circ} \mathrm{C}$} \\
\hline \multicolumn{1}{c}{ Initiator } & {$[\mathrm{C}], M$} & Yield, \% & {$[\eta]$} \\
\hline $\mathrm{BF}_{3} \mathrm{OEt}_{2}$ & 0.01 & - & - \\
$\mathrm{BF}_{3} \mathrm{OEt}_{2}$ & 0.05 & 0 & - \\
$\mathrm{TiCl}_{4}$ & 0.01 & 90 & 0.07 \\
$\mathrm{SnCl}_{4}$ & 0.01 & 25 & 0.09 \\
$\mathrm{H}_{2} \mathrm{SO}_{4}$ & 0.05 & - & - \\
$\mathrm{EtAlCl}_{2}$ & 0.02 & 70 & 0.10 \\
$\mathrm{BF}_{3} \mathrm{gas}^{2}$ & - & 100 & 0.08 \\
$\mathrm{AlBr}_{3}$ & 0.02 & 90 & 0.07 \\
$\mathrm{TiCl}_{4}^{\mathrm{a}}$ & 0.01 & 15 & 0.03 \\
$\mathrm{TiCl}_{4}{ }^{\mathrm{a}}+\mathrm{N}_{2}$ & 0.01 & 3 & - \\
$\mathrm{\theta}_{2} \mathrm{20}^{\circ} \mathrm{C}$
\end{tabular}

a $\theta, 20^{\circ} \mathrm{C}$; [Naphthalene], $0.1 \mathrm{M}$.

(B) 4-Methoxy-1-vinylnaphthalene: $\theta=-72^{\circ} \mathrm{C}$

\begin{tabular}{llcrl}
\hline \multicolumn{1}{c}{ Initiator } & $\begin{array}{c}{[\mathrm{M}],} \\
M\end{array}$ & \multicolumn{1}{c}{$[\mathrm{C}]}$, & $\begin{array}{c}\text { Yield, } \\
\%\end{array}$ & {$[\eta]$} \\
\hline $\mathrm{BF}_{3} \mathrm{OEt}_{2}$ & 0.36 & 0.05 & 100 & 0.27 \\
$\mathrm{BF}_{3} \mathrm{OEt}_{2}$ & 0.36 & 0.01 & 100 & 0.68 \\
$\mathrm{BF}_{3} \mathrm{OEt}_{2}$ & 0.36 & 0.0001 & 5 & 3.00 \\
$\mathrm{BF}_{3} \mathrm{OE}_{2}$ & 0.155 & 0.01 & 100 & 1.70 \\
$\mathrm{BF}_{3}$ gas & 0.3 & - & 100 & 0.24 \\
$\mathrm{TiCl}_{4}$ & 0.155 & 0.05 & 100 & 0.15 \\
\hline
\end{tabular}

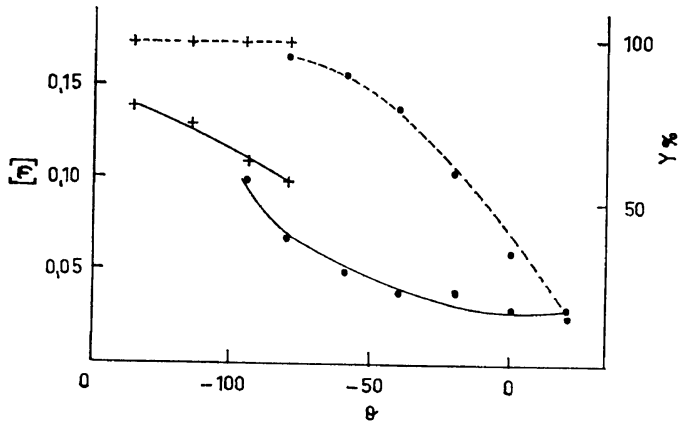

Figure 1. Homopolymerization of 1-vinylnaphthalene. Variations of the yield $Y(\%$, dashed line $)$ and of the intrinsic viscosity $[\eta]\left(100 \mathrm{~cm}^{3} \mathrm{~g}^{-1}\right.$, solid line $)$ with respect to the temperature of polymerization $\theta$ $\left({ }^{\circ} \mathrm{C}\right):\left[\mathrm{TiCl}_{4}\right], 0.01 \mathrm{M} ;[\mathrm{M}]_{0}, 0.15 \mathrm{M}$; solvent, $(\bullet)$ $\mathrm{CH}_{2} \mathrm{Cl}_{2} ;(+) \mathrm{C}_{2} \mathrm{H}_{5} \mathrm{Cl}$.

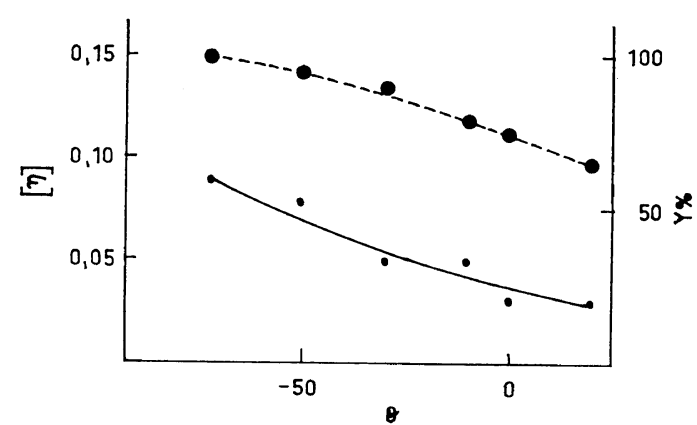

Figure 2. Homopolymerization of 2-vinylnaphthalene. Variations of the $Y(\%$, dashed line $)$ and of the intrinsic viscosity $[\eta]\left(100 \mathrm{~cm}^{3} \mathrm{~g}^{-1}\right.$, solid line $)$ with respect to the temperature of polymerization $\theta\left({ }^{\circ} \mathrm{C}\right)$ : $\left[\mathrm{TiCl}_{4}\right], 0.01 \mathrm{M} ;[\mathrm{M}]_{0}, 0.17 \mathrm{M}$.

is below $0.002 M$, the yield is almost zero.

The influence of the polymerization temperature on yield and $[\eta]$ is shown in Figure 1. The polymers have molecular weights between 5000 and 15000. We did not succeed in determining the nature of the end groups.

\section{Homopolymerization of 2-Vinylnaphthalene}

We worked only with $\mathrm{TiCl}_{4}$ as initiator. In the same way as for 1-vinylnaphthalene, yield and [ $\eta]$ are independent of $[\mathrm{M}]$ and $[\mathrm{C}]$. When $[\mathrm{C}]$ is below $0.003 M$, the yield is almost zero. When [C] is above $0.003 \mathrm{M}$, the yield is quantitative. The influences of the polymerization temperature $\theta$ on yield and $[\eta]$ are shown in Figure 2 and will be discussed later. 
Thermodynamic and Kinetic Study of the Cationic Polymerization of 1-Vinyl- and 2-Vinylnaphthalenes

The temperature was recorded with a recording millivoltmeter, a Wheatstone bridge, and a platinum resistance immersed in the polymerization solution, as described by Cheradame. ${ }^{18}$

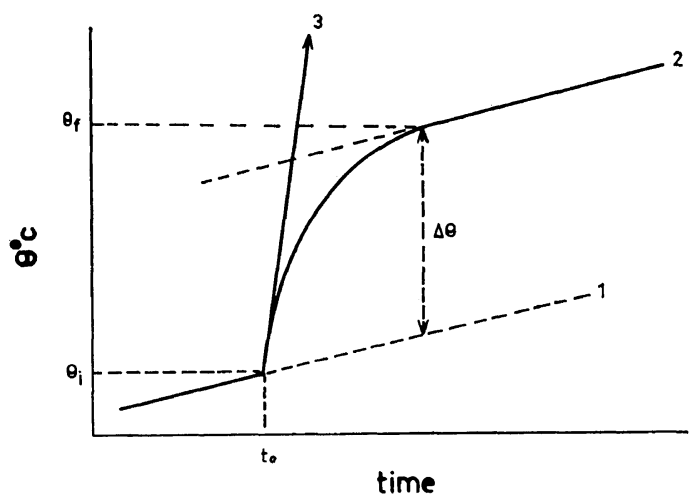

Figure 3. General trend of a thermogram for a homopolymerization (variations of the temperature $\theta\left({ }^{\circ} \mathrm{C}\right)$ with the time).

The trend of the thermograms is shown in Figure 3. The slope of straight line 1 represents the rate of the spontaneous heating at the temperature $\theta$ and the slope of straight line 3 represents the rate of heating during the polymerization. The initial rate of polymerization $R_{0}$ is given by the relation

$$
R_{0}=\text { slope } 3 \text {-slope } 1
$$

In addition, the difference of temperature $\Delta \theta$ allows us to obtain the value of the polymerization enthalpy, $\Delta H_{\mathrm{ss}}$. The polymerization enthalpies have been determined for both 1-vinyl- and 2vinylnaphthalenes at various monomer concentrations in the range of $0.065-0.25 \mathrm{M}$ and with various $\mathrm{TiCl}_{4}$ concentrations in the range of $0.8 \times 10^{-3}$ $1.75 \times 10^{-3} M$ (Table II). The calibration of the

Table II. The enthalpy of polymerization for 1-vinyl- and 2-vinylnaphthalenes,

$$
-\Delta H_{\mathrm{ss}}
$$

\begin{tabular}{lccc}
\hline Monomer & $\begin{array}{c}\theta, \\
{ }^{\circ} \mathrm{C}\end{array}$ & $\begin{array}{c}-\Delta H_{\mathrm{ss}}, \\
\mathrm{kcal} \mathrm{mol}^{-1}\end{array}$ & $\begin{array}{c}\text { Number of } \\
\text { measurements }\end{array}$ \\
\hline 1-Vinyl & -70 & $15 \pm 1$ & 8 \\
& -30 & $18 \pm 0.7$ & 3 \\
2-Vinyl & -70 & $15 \pm 1$ & 1 \\
\hline
\end{tabular}

apparatus, the measure of $\Delta T$, and the calculation of $\Delta H_{\mathrm{ss}}$ have been done according to ref 18 .

\section{Kinetic Determinations}

Until now only qualitative determinations of the water content influence have been performed. An important decrease of the polymerization rate is observed when water is added. The present results were obtained after a careful dehydration of the solvent and of the reactant. The content of residual water is such that the conversion for the polymerization of isobutylene is $10 \%$. According to $\mathrm{Plesch}^{20}$ this corresponds to $10^{-5} \mathrm{~mol} l^{-1}$.

In plotting $R_{0}$ against [M] $]_{0}$ for 1-vinylnaphthalene (Figure 4) we do not see any irregularities near the origin. Thus, externally the propagation is of first order with respect to the monomer.

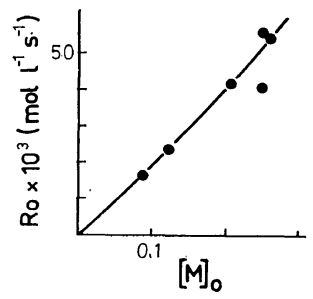

Figure 4. Homopolymerization of 1-vinylnaphthalene. Variations of the initial rate of polymerization $R_{0}$ with respect to the initial monomer concentration $\left[\mathrm{M}_{0}\right] ;\left[\mathrm{TiCl}_{4}\right], 1.6 \times 10^{-3} \mathrm{M}$.

The internal order determined by Chang's method $^{21}$ is one; the variations of $\log \left([\mathrm{M}]_{0} /[\mathrm{M}]\right)$ with respect to the time for 1-vinylnaphthalene are shown in Figure 5. Theoretically, a straight line should be obtained, but, in fact the rate constant depends on the temperature. If the temperature elevation during the polymerization is large, the relation between $\log \left([\mathrm{M}]_{0} /[\mathrm{M}]\right)$ and $t$ is no longer linear and the pattern is a curve instead of a straight line. This is what we observed (Figure 5, curve a) when the temperature elevation $\Delta \theta$ is above $10^{\circ} \mathrm{C}$; when $\Delta \theta$ is below $3^{\circ} \mathrm{C}$ a straight line is obtained (line $b$ ).

Let $\Delta \theta$ be the increase of temperature after a time of polymerization $t$; line $\mathrm{b}$ has been obtained at $\theta=203 \mathrm{~K}$. Consequently:

$$
\log \left(\frac{[\mathrm{M}]_{0}}{[\mathrm{M}]}\right)_{\mathrm{b}}=A \exp \left(-\frac{\Delta H^{\neq}}{203 R}\right) \times[\mathrm{C}]_{0} t
$$

and 


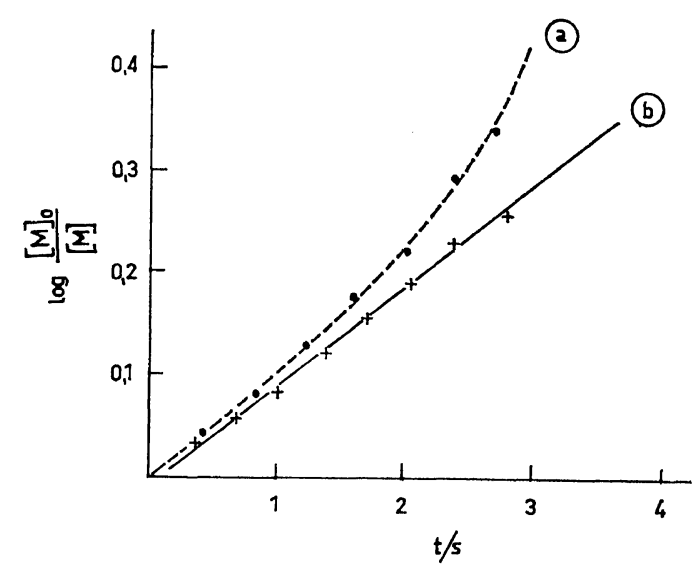

Figure 5. Homopolymerization of 1-vinylnaphthalene. Variations of $\log [\mathrm{M}]_{0} /[\mathrm{M}]$ with respect to the time (sec): $\left[\mathrm{TiCl}_{4}\right], 1.6 \times 10^{-3} \mathrm{M} ;[\mathrm{M}]_{0}=0.26 \mathrm{M}$ for curve a and 0.086 for curve $b$. For explanation of a and $b$, see the text.

$$
\log \left(\frac{[\mathrm{M}]_{0}}{[\mathrm{M}]}\right)_{\mathrm{a}}=A \exp \left(-\frac{\Delta H^{\neq}}{(203+\Delta \theta) R}\right) \times[\mathrm{C}]_{0} t
$$

The subscripts $a$ and $b$ refer to the curves $a$ and $b$ so that

$$
\frac{\log \left(\frac{[\mathrm{M}]_{0}}{[\mathrm{M}]^{\mathrm{a}}}\right)_{\mathrm{a}}}{\log \left(\frac{[\mathrm{M}]_{0}}{[\mathrm{M}]}\right)_{\mathrm{b}}}=\exp \left(\frac{-\Delta H^{\neq}}{R} \times \frac{\Delta \theta}{41200+230 \Delta \theta}\right)
$$

From curves $a$ and $b$, the following value is obtained for $\Delta H^{\neq}$:

$$
\Delta H^{\neq}=7.5 \pm 2.5 \mathrm{kcal} \mathrm{mol}^{-1}
$$

This result will be discussed later.

If we apply the Arrhenius relation to the values of $R_{0}$ determined at -30 and $-70^{\circ} \mathrm{C}$, we obtain

$$
\Delta H^{\neq}=6.6 \pm 1 \mathrm{kcal} \mathrm{mol}^{-1}
$$

which is in agreement with the former value, but is based on the assumption that the initial concentration of active species is the same at -30 and $-70^{\circ} \mathrm{C}$.

Only one kinetic determination has been done for 2-vinylnaphthalene, with $[\mathrm{M}]=0.25 \mathrm{M},\left[\mathrm{TiCl}_{4}\right]=$ $1.6 \times 10^{-3}, \theta=-70^{\circ} \mathrm{C}$; the polymerization rate was exactly the same as for 1-vinylnaphtalene.

\section{DISCUSSION}

\section{Molecular Weights}

The homopolymerization of 1- and 2-vinylna- phthalenes provides only low-molecular-weight polymers. We have shown in previous works ${ }^{4,6}$ that, in a general way, this was the case for the vinyl aromatic monomers with several aromatic rings. This was also what we observed with benzindenes ${ }^{1}$ whose polymers have a very much lower molecular weight than those of indene. This decrease is probably due to chain-transfer reactions with the monomer and polymer aromatic rings; the relative transfer constants are now being determined ${ }^{22}$ in our laboratory. It is found from a close examination of the quantum chemical characteristics of these monomers, which were determined by Hückel's method, that this transfer reactions are probably important.

The numbering of the monomers will be the following.<smiles>C=Cc1ccc2ccccc2c1</smiles><smiles>C=Cc1ccccc1</smiles>
II<smiles>[CH]=Cc1ccc(OC)c2ccccc12</smiles>

The superdelocalizability $S_{r}$ at the various aromatic carbons $r$ is listed in Table III.

The superdelocalizability differences between the carbon 12 (where the carbocation attack occurs in normal propagation) and the aromatic carbon with the highest superdelocalizability are

$$
\left.\begin{array}{l}
S_{12-4}=0.266 \\
S_{12-8}=0.275 \\
S_{12-1}=0.157
\end{array}\right\} \text { for 1-vinylnaphthalene }
$$

and

$$
S_{8-6}=S_{8-2}=0.335 \text { for styrene }
$$

The value of $S_{12-1}$ for 2-vinylnaphthalene is much smaller than the relative value for 1-vinylnaphthalene. However, the probability of an attack of carbon 1 by a carbocation is very small because this carbon is ortho to vinyl group and sterically hindered. The most probable attack is on carbon 8 , and in that case $S_{12-8}$ (2-vinylnaphthalene) 
Table III. Values of superdelocalizabilities $S_{r}$ and stabilization energies $(\Delta E)_{\mathrm{r}}{ }^{s}$ with regards to styryl cation for 1-vinyl-, 2-vinyl-, and 4-methoxy-1-vinylnaphthalenes (V1N, V2N, 4MeOV1N), and styrene (St) according to the Hückel method

\begin{tabular}{|c|c|c|c|c|c|c|c|c|c|c|c|c|c|c|}
\hline & & \multicolumn{13}{|c|}{ Carbon atoms } \\
\hline & & 1 & 2 & 3 & 4 & 5 & 6 & 7 & 8 & 9 & 10 & 11 & 12 & 13 \\
\hline \multirow[t]{2}{*}{ V1N } & $S_{r}$ & 0.899 & 1.015 & 0.863 & 1.108 & 1.015 & 0.869 & 0.900 & 0.978 & 0.752 & 0.701 & 0.899 & 1.374 & \\
\hline & $(\Delta E)_{r}^{s}$ & 0.664 & 0.745 & 0.651 & 0.800 & 0.745 & 0.655 & 0.674 & 0.722 & 0.577 & 0.544 & 0.673 & 0.973 & \\
\hline \multirow[t]{2}{*}{$\mathrm{V} 2 \mathrm{~N}$} & $S_{r}$ & 1.139 & 0.796 & 0.932 & 0.985 & 0.991 & 0.900 & 0.873 & 1.021 & 0.700 & 0.739 & 0.909 & 1.296 & \\
\hline & $(\Delta E)_{\mathrm{r}}{ }^{s}$ & 0.821 & 0.621 & 0.695 & 0.726 & 0.730 & 0.674 & 0.657 & 0.748 & 0.544 & 0.568 & 0.679 & 0.927 & \\
\hline \multirow[t]{2}{*}{$\mathrm{St}$} & $S_{r}$ & 0.761 & 0.931 & 0.829 & 0.911 & 0.829 & 0.931 & 0.911 & 1.266 & - & - & - & 一 & \\
\hline & $(\Delta E)_{\mathrm{r}}{ }^{s}$ & 0.580 & 0.695 & 0.631 & 0.681 & 0.631 & 0.695 & 0.681 & 0.910 & 一 & - & - & - & \\
\hline $4 \mathrm{MeO}-$ & & 1.097 & 1.007 & 1.076 & 1.061 & 1.011 & 0.918 & 0.900 & 1.019 & 0.752 & 0.758 & 0.893 & 1.568 & 1.209 \\
\hline $\mathrm{V} 1 \mathrm{~N}$ & $(\Delta E)_{r}{ }^{s}$ & 0.778 & 0.740 & 0.775 & 0.766 & 0.742 & 0.683 & 0.673 & 0.746 & 0.577 & 0.578 & 0.670 & 1.084 & 0.823 \\
\hline
\end{tabular}

$>S_{12-4}$ (1-vinylnaphthalene).

Now, we have shown ${ }^{23}$ that the transfer reactions were mainly of the Friedel-Crafts type

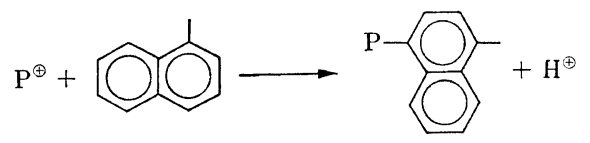

and that, consequently, the smaller the superdelocalizability difference $S_{12-r}$ between the carbon 12 and a carbon $r$ of the aromatic ring, the more important the contribution of transfer reactions with monomer. It appears that this difference is really smaller for 1-vinyl and 2-vinylnaphthalene than for styrene. Moreover, more carbons are able to participate in this transfer reaction for vinylnaphthalenes than those for styrene.

In this context it is interesting to mention that with 4-methoxy-1-vinylnaphthalene we obtained high-molecular-weight polymers $([\eta]=3.0){ }^{5}$ The comparison of this compound with the vinylnaphathalenes suggests that the most effective transfer site (carbon 4) is no longer accessible. Moreover, the superdelocalizability difference between carbon 12 and carbon 3 (now the most probable site for an electrophilic attack) is 0.492 , which is very large compared to the former values. Thus, the high molecular weight of polymer obtained from 4methoxy-1-vinylnaphthalene is not only due to high polymerizability of the monomer but also due to low reactivity for chain transfer.

The contribution of transfer reactions is also in agreement with the decrease of the molecular weight observed when the polymerization tempera- ture increases, the absolute value of activation energy for transfer reactions being generally higher than that for propagation. We have at this time a study in progress on this topic. ${ }^{22}$

Moreover, when naphthalene is added to the polymerization solution of 1-vinyl or 2-vinylnaphthalenes the molecular weight decreases drastically, which is in agreement with a Friedel-Crafts attack of the aromatic rings (Table I).

This alkylation of the monomer is in fact a new variant of the alkylation of solvent toluene or polystyrene by growing polystyryl ions. ${ }^{24,25,26}$

\section{Thermodynamic and Kinetic Values}

The values of enthalpy of polymerization of both vinylnaphthalenes (Table II) are of the same order of magnitude as those obtained for various substituted indenes and for styrene.

$$
\begin{array}{ll}
\text { Styrene } & -16.1 \mathrm{kcal} \mathrm{mol}^{-127} \\
\text { Indene } & -13.9 \mathrm{kcal} \mathrm{mol}^{-118} \\
\text { 4, 7-Dimethylindene } & -15.5 \mathrm{kcal} \mathrm{mol}^{-128,29} \\
\text { 4, 5, 6, 7-Tetramethylindene } \\
\multicolumn{2}{c}{-18.0 \mathrm{kcal} \mathrm{mol}^{-128,29}}
\end{array}
$$

The value found for the activation enthalpy of the polymerization of 1-vinylnaphthalene $\Delta H^{\neq}=$ $7.5 \pm 2.5 \mathrm{kcal} \mathrm{mol}^{-1}$ is relatively inaccurate-due to our way of determination-but in agreement with the value that we obtained by the Arrhenius method. Moreover, in another study ${ }^{7}$ we obtained the activation enthalpy and entropy differences for 1-vinyl- and 2-vinylnaphthalenes and styrene by reactivity ratio determinations (Table IV).

If we accept the value $\Delta H_{22}^{\neq}=8 \mathrm{kcal} \mathrm{mol}^{-1}$ reported by Higashimura ${ }^{30}$ as within an order of 


\section{Bunel and E. MAREChal}

Table IV. Values of activation enthalpy and entropy differences for the pairs 1-vinylnaphthalene-styrene (VIN/St) and 2-vinylnaphthalene-styrene (V2N/St) (Index 1 for vinylnaphthalenes and index 2 for styrene)

\begin{tabular}{lcc}
\hline & $\begin{array}{c}\Delta H_{22}^{\neq}-\Delta H_{21}^{\neq}, \\
\mathrm{kcal} \mathrm{mol}^{-1}\end{array}$ & $\begin{array}{c}\Delta S_{22}^{\neq}-\Delta S_{21}^{\neq}, \\
\mathrm{cal} \mathrm{mol}^{-1} \mathrm{deg}^{-1}\end{array}$ \\
\hline V1N/St & 1.3 & 5.2 \\
V2N/St & 1.1 & 4.9 \\
\hline
\end{tabular}

magnitude, we see that the enthalpy of activation for the reaction of 1-vinylnaphthalene with styryl cation is almost the same as that for the reaction of 1-vinylnaphthalene with the 1-vinylnaphthalene cation.

Our single rate determination for 2-vinylnaphthalene gave the same $R_{0}$ as for 1-vinylnaphthalene at $-70^{\circ} \mathrm{C}$. This observation fits with the quantum chemical characteristics of these monomers; the stabilization energy calculated according to Yonezaw ${ }^{31}$ by the Hückel method is slightly greater for 1-vinyl- than for 2-vinylnaphthalene but of the same order of magnitude (see Table III). However, $R_{0}$ is associated not only with the reactivity in propagation but also with those in initiation and termination; thus the correlation of $R_{0}$ with the stabilization energy is perhaps questionable, at least for termination.

Moreover, in another work we determined the values of reactivity ratios $^{7}$ for the systems 1vinylnaphthalene-styrene and 2-vinylnaphthalene-styrene and found that they are very similar. This fact is also in agreement with the very similar values of $R_{0}$ for 1 - and 2-vinylnaphthalenes.

\section{REFERENCES}

1. E. Marechal and G. Chaintron, Bull. Soc. Chim., 987 (1967).

2. P. Belliard and E. Marechal, Bull. Soc. Chim., 4255 (1972).

3. S. Cohen, P. Belliard, and E. Marechal, Polymer, 14, 352 (1973).

4. J. P. Laguerre and E. Marechal, Ann. Chim., (Paris), 9, 163 (1974).

5. C. Bunel, S. Cochen, J. P. Laguerre, and E. Mare- chal, Polym. J., 7, 320 (1975).

6. S. Cohen and E. Marechal, J. Polym. Sci., Polym. Symp., No. 52, 83 (1975).

7. C. Bunel, Ph. Blin, Cho Won-Jei, and E. Marechal, to be published.

8. Standard Oil Development Co., British Patent 598, 484, June 20, 1947.

9. Rütgerswerke A. G., British Patent 725, 459, March 2, 1955.

10. S. A. Zonis, J. Gen. Chem. (U.S.S.R.), 9, 119 (1939).

11. E. Berger, Bull. Soc. Chim., 338 (1906).

12. W. Davies and Q. N. Porter, J. Chem. Soc., 459 (1957).

13. G. Champetier, M. Fontanille, A. C. Korn, and P. Sigwalt, J. Polym. Sci., 58, 911 (1962).

14. H. Cheradame and P. Sigwalt, C. R. Acad. Sci., 260, 159 (1965).

15. H. Cheradame and P. Sigwalt, C. R. Acad. Sci., 259, 4273 (1965).

16. P. Sigwalt and J. P. Vairon, Bull. Soc. Chim., 482 (1964).

17. Nguyen Anh Hung, Thèse de $3^{\circ}$ Cycle, Paris, 1970.

18. H. Cheradame, J. P. Vairon, and P. Sigwalt, Eur. Polym. J., 4, 13 (1968).

19. R. H. Biddulph and P. H. Plesch, Chem. Ind. (London), 1482 (1959).

20. R. H. Biddulph, P. H. Plesch, and P. P. Rutherford, J. Chem. Soc., 275 (1965).

21. W. H. Chang, J. Phys. Chem., 61, 819 (1957).

22. Ph. Blin, C. Bunel, and E. Marechal, to be published.

23. H. Garreau and E. Marechal, Eur. Polym. J., 9, 263 (1973).

24. P. H. Plesch, J. Chem. Soc., 1662 (1953).

25. G. F. Endres, V. G. Kamath, and C. G. Overberger, J. Am. Chem. Soc., 84, 4813 (1962).

26. C. G. Overberger and M. G. Newton, J. Am. Chem. Soc., 82, 3622 (1960).

27. R. H. Biddulph, W. R. Longworth, J. Penfold, P. H. Plesch, and P. P. Rutherford, Polymer, 1, 52 (1960).

28. E. Marechal, P. Evrard, and P. Sigwalt, Bull. Soc. Chim., 1981 (1969).

29. E. Marechal, J. Polym. Sci., Part A-1, 8, 2867 (1970).

30. T. Higashimura in "Structure and Mechanism in Vinyl Polymerization," T. Tsuruta and K. F. O'Driscoll, Ed., Dekker, New York, N. Y., 1969, p 340.

31. K. F. O'Driscoll and T. Yonezawa, Rev. Macromol. Chem., 1, 1 (1967). 